\title{
Morphometric Study of Changes in GAD 65 Expressing Beta Cell Mass In The Islets Of Langerhans In Pregnant Mice
}

\author{
Alaa K. Al-asadi ${ }^{\mathrm{a}}$, May F. Al-Habib ${ }^{\mathrm{b}}$, Ula M. Al-Kawaz ${ }^{\mathrm{a}}$, Mohammad Oda Selman ${ }^{\mathrm{a}}$, Imad Matloub Al-Ani ${ }^{\text {c* }}$ \\ ${ }^{a}$ Department of Applied Embryology/ High Institute of Infertility Diagnosis and ART/ Al-Nahrain University, \\ Baghdad, Iraq. \\ ${ }^{b}$ Department of Histology and Embryology, College of Medicine Al-Nahrain University, Baghdad, Iraq. \\ 'Department of Basic Medical Science, Kulliyyah of Medicine, International Islamic University, Kuantan, \\ Malaysia.
}

\section{ABSTRACT}

INTRODUCTION: This study explored the adaptive changes in pancreatic islets by assessing the maternal pancreatic B-cell mass (PBCM), islets size, number, shape, distribution and vascularity using the anti-GAD65 $A b$ as a marker in pregnant mice. MATERIALS AND METHODS: Fourty female Swiss-Webster mice were randomly divided into two age matched groups of 20 animals each, pregnant and control (non-pregnant) groups. The pregnant mice were sacrificed at Day 19 of gestation and the control group was sacrificed 19 days after observation in the same environmental conditions. Specimens of pancreata were fixed in 10\% formal-saline, and processed for light microscopy. Paraffin sections were stained with chromogen DAB. Image scope (APERIO) with Image J software was used for morphometric study. RESULTS: Islets cells showed specific reaction with GAD65 Ab. There was an increase in the cellularity and vascularity of the PBCM. A significant increase in the islets area of the pregnant group ranging between $32-723 \mu \mathrm{m}^{2}$ in comparison with the control group that ranged between $5-210 \mu \mathrm{m}^{2}$, the islet size and numbers also increased; there were numerous newly formed islets and coalescence of adjacent islets, positive reactivity of B-cells toward antiGAD65 during pregnancy, the mean of positive granulation in PBCM in pregnant group was 8273.5 ${ } \mathrm{SE}$ 831.35 while in control group was $34 \pm$ SE 0.2. CONCLUSION: The changes for alteration in PBCM such as increase in cells number, size, positive anti-GAD65 reactivity and their vascularity during pregnancy is related to the adaptation for hormonal and nutritional demands of both foetus and mother.

KEYWORDS: B-cell mass, GAD65, islet of Langerhans, pancreas, pregnancy.

\section{INTRODUCTION}

The pancreas is a soft, elongated, flattened exocrine and endocrine gland surrounded by fine connective tissue; the exocrine pancreas that produces digestive enzymes and bicarbonate and the endocrine pancreas "pancreatic islets"; that are

Corresponding Author :

Prof. Dr. Imad M. Al-Ani

Department of Basic Medical Sciences,

Kulliyyah of Medicine,

International Islamic University Malaysia,

P.O. Box 141, 25710, Kuantan, Malaysia.

Tel : 017-9776014

Emails : imad_alani@yahoo.com,

imadmatloub@iium.edu.my scattered throughout the pancreatic acini. The pancreatic islets are rounded-oval clusters of cells that occupy about $2 \%$ of the total pancreatic tissue; they are highly vascularized clusters of different types of pale staining polygonal cells surrounded by reticular fibre networks. These variations in number of the islets and the size and distribution of cells within them depend on: region, age, disease and physiological state, the islets are most numerous in the tail of the pancreas. ${ }^{1-3}$ There are three major cell types in the pancreatic islets: $\alpha$-, $B$ - and $\delta$-cells for production of glucagon, insulin, and somatostatin respectively; a classification based on the pioneer works. ${ }^{4}$ In addition, other cell types (C, E, F, V and X or $\mathrm{PP}$ ) responsible for the production of pancreatic polypeptides were rarely observed in few animal 
species such as dogs, guinea pigs, rabbits and mice. ${ }^{1,5}$ The pancreatic islets range in size from clusters of a few cells to several thousand cells, scattered near large blood vessels. The number and size of pancreatic islets is influenced by islet embryonic/neonatal development, pregnancy, aging, obesity and by growth/shrinkage and fusion/ fission processes under physiological and pathological conditions. ${ }^{6}$ Pancreatic B-Cell Mass $(P B C M)$ regulation represents a critical issue for understanding diabetes. In rodents, the process of PBCM formation at a high rate in the foetal life, starting from the $16^{\text {th }}$ day post-conception and continues in the newborn. ${ }^{7,8}$ The maternal pancreas during pregnancy adapts to increase insulin resistance and metabolic demand by up-regulating PBCM; B-cell hypertrophy, increase in insulin synthesis and insulin content, and lowering of the threshold for glucose-stimulated insulin secretion. ${ }^{9}$

Glutamic acid decarboxylase (GAD) is the major enzyme in the B-cells, it involves two major protein isoforms that catalyse the gamma-aminobutyric acid (GABA) synthesis; GAD65 is the product of a gene located on chromosome $10 .^{10}$ GAD65 is mostly detected in synaptic-like vesicles, and has been localized in the large dense-core insulin secretory granules of the B-cells. ${ }^{11}$ To date there is no known published histological study demonstrating the presence of GAD65 in the maternal pancreatic islets during pregnancy. Therefore, the objectives of this study were to evaluate the modifications induced by pregnancy in the maternal pancreatic islets including size, number and shape and to assess the $B$-cells changes in the pancreatic islets in pregnant and non-pregnant mice using anti GAD65 Ab.

\section{MATERIALS AND METHODS}

\section{Animals}

Fourty female Swiss-Webster mice (10-12 week old), obtained from the animal house at the Higher Institute of Infertility Diagnosis and Assisted Reproductive Technology, Al-Nahrain University, were used for this study. The mice were kept under suitable conditions; room temperature at $24 \pm 2{ }^{\circ} \mathrm{C}$ and 12 hours/day light cycle. The animal study protocol was conducted in compliance with the approval of the Department of Histology and Embryology, College of Medicine / Al-Nahrain University.

\section{Experimental Design}

The animals were randomly divided into two groups of 20 age-matched; the control and the pregnant groups. Vaginal smears for all animals were performed to determine the regularity of at least three consecutive oestrus cycles. Then, the animals from the pregnant group that are in oestrus phase were allowed to mate with mature healthy males; after examination of the vaginal plug to observe spermatozoa, at which time the gestation period has started and considered the first day of pregnancy. ${ }^{12}$ At Day 19 after gestation, the pregnant mice were sacrificed; the mice of the control group were also sacrificed after 19 days of observation in the same environmental conditions. The abdomen was incised transversely, and the pancreas was harvested. The pancreatic tissues were fixed in a $10 \%$ formal-saline for 48 hour and processed for light microscopy. Paraffin sections of $4 \mu \mathrm{m}$ thickness were cut using rotary microtome, collected on positively charged slides for anti-GAD65 immunohistochemmical staining and plain slides for Harris Hematoxylin and Eosin staining. Serial sections of the pancreata from both groups were studied to calculate the number of the pancreatic islets in each section followed by measuring the means of the pancreatic islets number. 1280 sections were taken from each pancreas.

Morphometric image analysis was performed using the Image-J software (Java-based image processing program developed at the National Institutes of Health, USA), version 1.47-(http://imagej.nih.gov/ $\mathrm{ij} /$ docs/guide). The technique of immuned $\mathrm{Cruz}^{\mathrm{TM}}$ mouse LSAB staining system (sc2050) was applied using $D A B$ chromogen and HRP substrate to each slide until light brown stain was visible, rinsed with deionized water, dehydrated; sections then cleared with xylene. The Aperio positive Pixel Image Scope V11 count algorithms program was used to quantify the amount of specific colour in the tissue sections as shown in (Figure $1 \mathrm{~A}$ ).

\section{Statistical analysis}

The IBM Corp. SPSS Statistics for Windows, Version 23 Armonk, NY: IBM Corp. was used to analyse the data. All data in this study are presented as mean \pm SEM. Data were analysed by Mann-Whitney $U$ test, the value of $p<0.05$ was considered as statistically significant. 


\section{RESULT}

\section{Histological examination of the endocrine pancreatic tissue}

The anti GAD65 Ab was used to demonstrate the presence of B-cells in the islets and to quantify the differences of activity of those cells between the pregnant and control groups. The pancreas of the control group showed normal structural features with mild reactivity of GAD65 in the cytoplasm of the islet cells and no expression of GAD65 in the nuclei or in the exocrine part (Figure 1B). The islets $B$-cells of the pregnant group showed specific reaction with GAD65 $\mathrm{Ab}$, while the exocrine pancreatic tissue showed no reactivity to the GAD65 Ab. The expression of GAD65 was seen mainly in the cytoplasm of the B-cells and the staining reactivity was not observed in the nuclei of the islet cells; the nuclei were stained with counter stain Harris Hematoxylin (Figures 1C \& 1D).

The anti GAD65 was a good marker to recognize the newly formed islets; even single $B$-cells were found scattered among the exocrine acini (Figure 2A). Some of the B-cells are seen as single or double cells dispersed between the acini starting to form new islets in the pregnant group; some of the B-cells are seen near the wall of the pancreatic duct (Figure 1D). Adjacent pancreatic islets coalesced to form large islets with highly positive cytoplasmic granulation and numerous blood vessels with different diameters were observed in pregnant group, the large islet shows strong positive granulation while the newly formed islets showed low affinity of granulation in pregnant group (Figure $2 \mathrm{~B})$. The reaction was not homogenous in the cytoplasm of B-cells, it was in a form of fine small granules in the cytoplasm of the pancreatic islets cells; the granules are yellowish to brownish in colour and more obvious in pregnant group than in those in control group (Figures $2 \mathrm{C} \& 2 \mathrm{D}$ ). The pancreatic islets tissue showed positive staining with anti GAD65 Ab DAB chromogen while the exocrine pancreatic showed negative reaction for these stains. There was variability in the positivity toward the anti GAD65 Ab DAB stains between the pregnant and control groups; the immunoreactivity of the control group islet cells was low, while the reactivity was highly detected in the cytoplasm of the B-cells of the pregnant group (Figure 2C \& 2D).
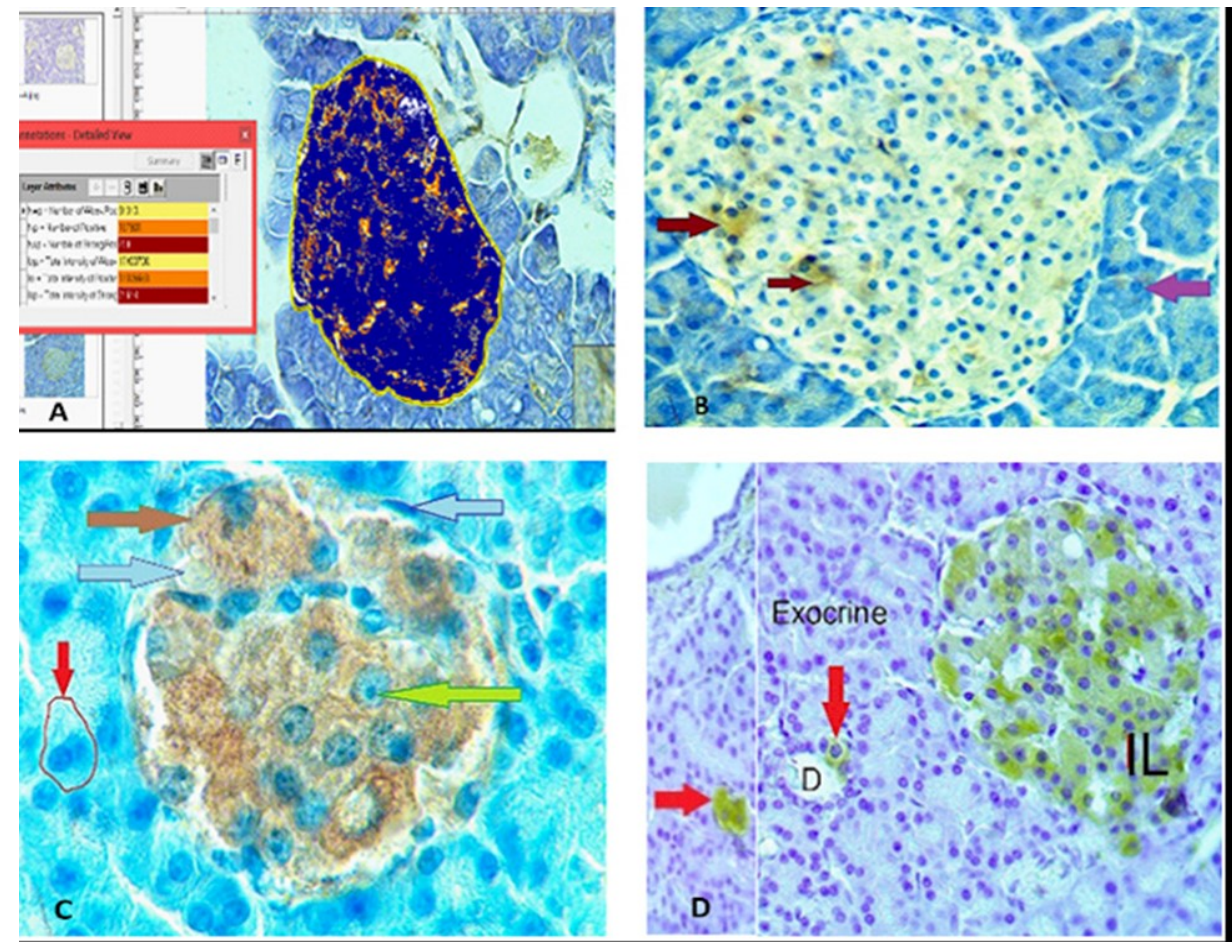

Figure 1: Photomicrographs of pancreas stained with GAD65 DAP (A); Snap shoot for the pancreatic section of pregnant group as analysed by Aperio positive pixel count Algorithm software display the pancreatic islet showing high detection of GAD65 in islet of Langerhans "orange spots" (400x magnification). (B); control group showing low detection of GAD65 in pancreatic islet cells cytoplasm (brown arrow) with no expression of GAD65 in the nucleus or in the exocrine part (violet arrow) (400x magnification) (C); pregnant group showing strong positive reaction in the islet cells cytoplasm of "brown arrow", with neither GAD65 expression in the nucleus "green arrow", nor in other islet cell types "blue arrow", or in the exocrine part "red arrow" (1000x magnification) (D); pregnant group showing a B-cell within the ductal wall "D" and a twin separated B-cells forming new islets of "red arrows" that demonstrated strong positive granulation reactivity with GAD65 taken brown colour "IL" (400x magnification) 

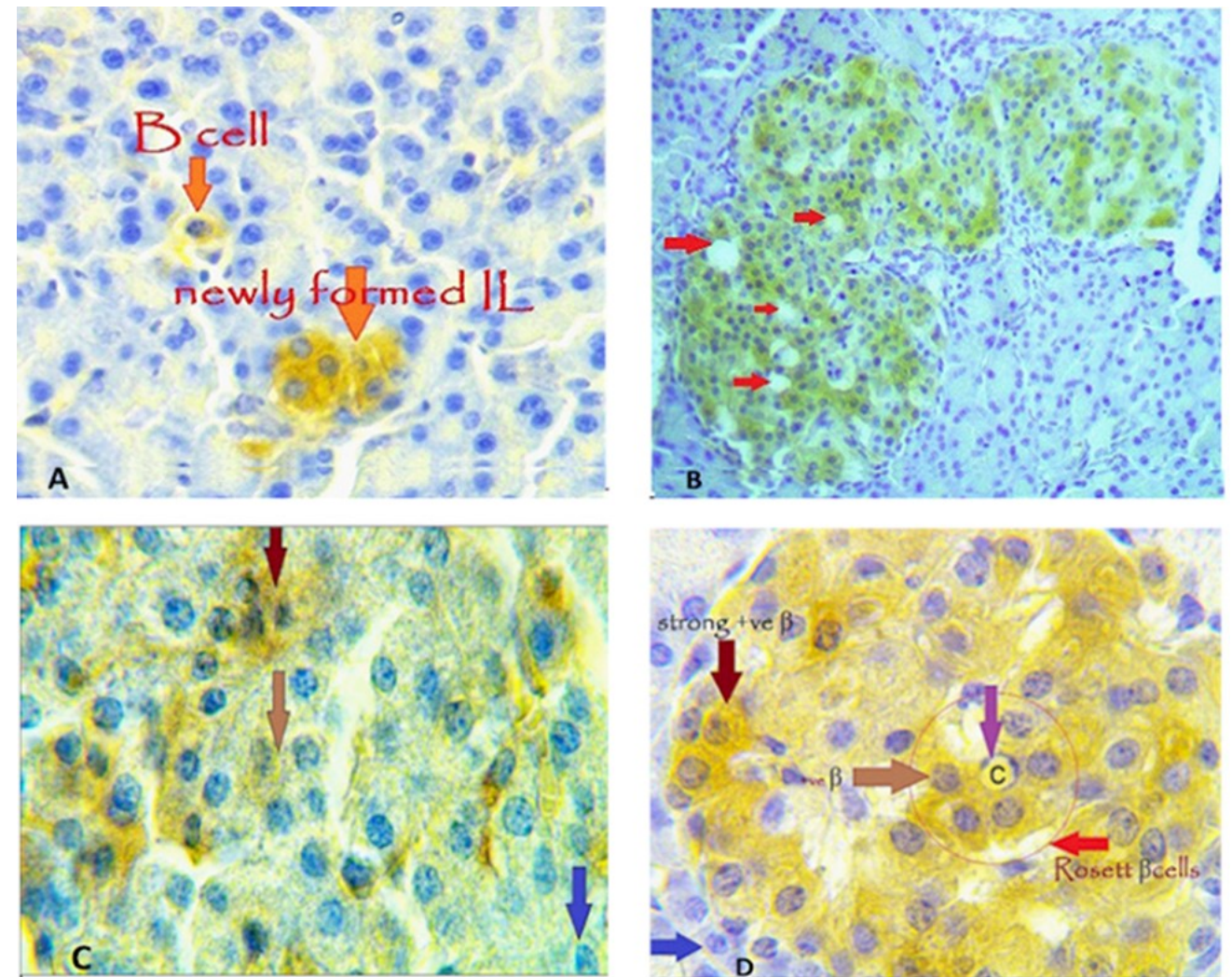

Figure II: Photomicrographs of pancreas stained with GAD65 DAP (A); pregnant group showing single $B$ cell and newly formed islet "IL" with strong positive granulation reactivity with GAD65 "orange arrows" (1000x magnification) (B); pregnant group showing coalescence of adjacent of pancreatic islets which with strong positive granulation reactivity with GAD65 and large number of capillaries "red arrows" (200x magnification) (C); control group showing variation reactivity for GAD65 e.g.: mild reactivity of the B-cell "dark brown arrow" and scant reactivity "light brown arrow" with no staining reactivity for other cell types in the pancreatic islet "blue arrow", (1000x magnification) (D); pregnant group showing rosette shape of B-cells around the capillary "c", strong positive reactivity of B cells "dark brown arrow" and mild reactivity of others "light brown arrow" in the pancreatic islet and no reactivity of the acinar cells "blue arrow" (1000x magnification)

\section{Morphometrical measurements of the endocrine pancreatic tissue}

The pancreatic islets and the whole pancreatic tissue was measured using Image-J software. The present study has found that the whole islets size in control group was $2262.1 \pm 56.5 \mu \mathrm{m}^{3}$ of the total pancreatic mass indicating that it occupies $1.098 \%$ of the total pancreatic tissue mass; while for pregnant group, the islets size was $5745.7 \pm 360.4 \mu \mathrm{m}^{3}$ of the total pancreatic representing $13.628 \%$ of the whole pancreatic tissue. The exocrine tissue also showed a slight size increment in pregnant group $194810.3 \pm 1919.2 \mu \mathrm{m}^{3}$ in comparison with the control group $190507.8 \pm 1980 \mu \mathrm{m}^{3}$; these expansions in the endocrine and exocrine tissues yielded much greater enlargement in the whole pancreatic tissue of the pregnant $200556 \pm 2438.7 \mu \mathrm{m}^{3}$ group as compared to the control $192769.8 \pm 1159.2 \mu \mathrm{m}^{3}$. The present study has demonstrated an increase in the number of the pancreatic islets per section of the pregnant group $6.6 \pm 0.327$ in compare with the control group $1.3 \pm 0.10$.
The pancreatic islets' area of the control group ranged between $51-210 \mu \mathrm{m}^{2}$ with a mean of $180.3 \pm 9.2 \mu \mathrm{m}^{2}$; while those of the pregnant group showed a higher increase in surface area ranging between $32-723 \mu \mathrm{m}^{2}$ with the mean of $457.6 \pm 20.4 \mu \mathrm{m}^{2}$. Statistical analysis of the islets' area showed a significant difference between these groups where $t=5.183$ ( $p$ value $\leq 0.05$ ). The area of the pancreatic islets in pregnant group was larger than the area of the islet cells in control group with the mean of $40.1 \pm 1.8 \mu \mathrm{m}^{2}$ and $25.15 \pm 1.5 \mu \mathrm{m}^{2}$ respectively.

\section{Evaluation of GAD65 expression in Islet of Langerhans}

The Aperio positive pixel count algorithm software was used in this study to evaluate and quantify the GAD65 enzyme in the pancreatic islets; the enzyme was restrictively detectable in B-cells cytoplasm. The staining intensity is represented by the calculated mean percentage positivity in the tissue 
sections for both pregnant and control groups. The staining reactivity was higher in the pregnant group than those in control group (Figures $2 \mathrm{C} \& 2 \mathrm{D}$ ). Statistical analysis has demonstrated a significant difference between the pregnant and control groups; the positive granulation in $\mathrm{PBCM}$ of the pregnant group was more than that of the control group with the mean of $223897.5 \pm 2196.7$ and $130142.2 \pm 987.3$ respectively $(p<0.05)$ - $(\mathrm{t}$-test $=2.02)$. Positive granulation was found in B-cell mass of the pregnant group with the mean of $8273.5 \pm 831.35$ which was more than in the control group at $34 \pm 0.2$ $(p<0.05)(\mathrm{t}$-test $=2.008)$.

\section{DISCUSSION AND CONCLUSION}

It is well known that the pancreatic B-cells synthesize and secrete the insulin required for optimal glucose homeostasis. PBCM is determined by the number and size of $B$-cells in the pancreatic islet, features that are regulated by cellular processes such as replication, loss, regeneration, hypertrophy and neogenesis. One of the most remarkable reversible $B$-cell adaptations occurs during pregnancy and postnatally. During pregnancy, the increase in maternal insulin resistance is compensated by maternal B-cell hyperplasia and hyper-functionality to maintain normal blood glucose levels. ${ }^{13,14}$ Feeding rats a low-protein diet during pregnancy reduces pancreatic islet area, decreases circulating corticosterone levels and consequently, cellular proliferation, growth, survival and death. ${ }^{15}$ The purpose of the present study was to assess the changes that might occur in the size, number and shape of B-cells of the pancreatic islets of pregnant mice using anti GAD65 $\mathrm{Ab}$ as a B-cell marker.

Increased insulin demand during pregnancy alters islet function and mass leading to gestational diabetes mellitus in predisposed individuals. ${ }^{16}$ The present study has demonstrated an increase in both the total pancreatic mass and the total pancreatic islets tissues during pregnancy; this is consistent with previous studies that observed expansion of pancreatic islets and $\mathrm{PBCM}$ in pregnant mice on day 14.5 of gestation. ${ }^{17}$ The pancreatic fractional B-cell area was increased by $\sim 1.4$-folds, with no change in mean $B$-cell size and there were more small islets rather than an increase in islet size or in the number of B-cell per islet and scattered B-cells were also noted to be increased in human pregnancy. ${ }^{18}$
The present study has also demonstrated an increase in the pancreatic islets number and the size in the pregnant mice. Previous studies have observed a higher number of small islets and single B-cells in the pancreata of pregnant women compared to nonpregnant women and related that to the B-cell regeneration ${ }^{18,19}$ or to islet cell proliferation in pregnant rats $^{20}$ or to $\mathrm{B}$-cell duplication in pregnant mice $^{21,22}$ or may be related to the formation of numerous, small islets and hypertrophy of the other islets by coalescence of adjacent ones associated with increase in their cellularity. ${ }^{23}$ Proliferation of new B-cells may take place during both embryonic and adult life, leading to the formation of new islets or "islet neogenesis", as a result of an increased physiological demand. ${ }^{24,25}$

There is controversy regarding the mechanisms underlying the expansion of B-cell mass. These mechanisms comprise duplication of preexisting Bcells, differentiation of progenitors within the ductal epithelium, trans-differentiation of acinar cells, and differentiation of pancreatic stem cells. ${ }^{18,24}$ Other studies in humans proposed that development of new islets is not from the duplication of B-cell in pre -existing islets as the main source of B-cell mass increase during pregnancy; this assumption was concluded from the finding of large number of small islets and single B-cells "scattered within the exocrine tissue" in pancreata of pregnant women, as small islets and single B-cell are frequently described as proof of B-cell regeneration. ${ }^{18,19}$ However, under significant regenerative pressure, Bcells neogenesis and trans-differentiation of other cell types to insulin-releasing cells have been described, for example, trans-differentiation from ato $B$-cells has been described after extreme B-cell loss. ${ }^{26,27}$

Pancreatic islet vascularization is critical for normal islet development, throughout pregnancy to adulthood development; endothelial cells are responsible for paracrine and blood-borne signals that contribute significantly to pancreas development, endocrine cell differentiation and Bcell proliferation, and secretory function. ${ }^{28,29}$ The exocrine as well as endocrine tissues of the pregnant mice of the present study displayed hypervascularity in comparison with control group; this is consistent with the increased complex capillary network penetrated the newly formed pancreatic islet in rats $^{30}$ and with the increased islet 
vascularization together with B-cell replication in pregnant rats. ${ }^{20}$ Placental lactogen hormone (PLH), produced only during pregnancy is the factor chiefly responsible for the mass increase of pancreatic islets, B-cells proliferation, islets hyperplasia, formation of numerous, small islets and coalescence of adjacent islets for improvement of their function. 31,32 In addition, expression of prolactin (PRL) receptor (PRLR), that binds both PRL and PLH, is also increased in maternal islets during pregnancy. ${ }^{14,33}$ Other studies have analysed the gene -expression arrangement in the islet during pregnancy in mice, focusing on gene alterations around gestational days 13-15 when proliferation of maternal B-cell starts. ${ }^{34,35}$ Hundreds of genes were altered in the islets during pregnancy, covering an extensive variety of cellular processes such as metabolism, growth, death, insulin secretion, development and cell interaction. ${ }^{14}$ In addition to the well-known effect of lactogens throughout maternal B-cell expansion, serotonin biosynthesis that is strongly induced during pregnancy plays a role in maternal B-cell expansion. ${ }^{17}$ Serotonin itself has been shown to enhance insulin synthesis and secretion on primary rat islets in vitro. ${ }^{36}$

Glutamic acid decarboxylase 65 (GAD65) is the major enzyme in the synthesis of $\gamma$-amino butyric acid (GABA) which is a potent inhibitory neurotransmitter and a critical component of neurophysiologic function. GAD65 is the product of a gene located on chromosome $10 .{ }^{10}$ Concentrations of GAD65 is controlled either by transcription or by mRNA splicing ${ }^{37}$ it is an essential protein for maintaining homeostasis and viability of complex organisms. ${ }^{38}$ It is also detected in the pancreatic islets where it is stored in synaptic-vesicles of the Bcell and may regulate proinsulin synthesis ${ }^{39}$ as it is separated from the large dense-core insulin secretory granules. ${ }^{11}$ So far, no histological study has been published to demonstrate the presence of GAD65 in the pancreatic islets. The present investigation has demonstrated GAD65 mainly in the cytoplasm of the B-cells of the pregnant mice; but neither in exocrine pancreatic tissue nor in the endocrine or exocrine pancreatic tissue of the control mice suggesting the enhanced synthesis of insulin in the pregnant mice.

Further ultrastructural and immunohistochemical studies using anti-GAD 65 on the maternal pancreas at different days of gestation are needed to study the changes in the pancreatic islets, B-cells proliferation and the PBCM expression.

In conclusion, the PBCM expansion demonstrated by $B$-cells proliferation, increased islet size, number and vascularization in pregnant mice and that GAD65 expression is useful marker for following up PBCM changes.

\section{Conflict of interest statement}

The authors declare no potential conflicts of interests.

\section{REFERENCES}

1. Bsoul MK, Qar JS, Al-Ani IM, et al. Ultrastructure of Pancreatic Endocrine Cells of the Single Hump Camel (Camelus dromedarius). Annals of Microscopy 2013; 13: 36-42.

2. Jo J, Kilimnik G, Kim A, et al. Formation of Pancreatic Islets Involves Coordinated Expansion of Small Islets and Fission of Large Interconnected Islet-like Structures. Biophysical Journal 2015; 101: 565-74.

3. Longnecker D. Anatomy and Histology of the Pancreas. In Pancreatitis. Edited by John A. 2016; Williams, American Pancreatic Association. ISBN: 978-1-60785-369-5.

4. Caramia F, Munger BL, Lacy PE. The ultrastructural basis for the identification of cell types in the pancreatic islets I. Guinea pig. Cell and Tissue Research 1965; 67: 533546.

5. Al-Ani IM. Histochemical and ultrastructural studies on the islets of Langerhans of lean and obese hyperglycemic mice with age. 1978; M. Phil thesis. The University of Aston in Birmingham. Birmingham, England.

6. Jo J, Hara M, Ahlgren U, et al. Mathematical models of pancreatic islet size distributions. Islets 2012; 4: 10-9.

7. Bouwens L, Rooman I. Regulation of Pancreatic Beta-Cell Mass. Physiological Reviews 2005; 85: 1255-70.

8. Marrif HI, Al-Sunousi SI. Pancreatic B Cell Mass Death. Front. Pharmacol 2016; 7: doi: 10.3389/fphar.2016.00083

9. Toselli $C$, Hyslop $C M$, Hughes $M$, et al. Contribution of a Non-B-Cell Source to B-Cell Mass during Pregnancy. PLOS ONE 2014; 9(6): 
e100398. https://doi.org/10.1371.

10. Towns R, Pietropaolo M. GAD65 autoantibodies and its role as biomarker of Type 1 diabetes and Latent Autoimmune Diabetes in Adults (LADA). Drugs Future 2011; 36(11): 1-14.

11. Buddhala C, Hsu CC, Wu JY. A novel mechanism for GABA synthesis and packaging into synaptic vesicles. Neurochem Int 2009; 55: 9-12.

12. Suckow M A, Danneman P, Brayton C. The Laboratory Mouse, Second Edition. 2012; CRC Press. ISBN: 9781439854211

13. Adeyemi DO, Komolafe OA, Adewole OS, et al. Histomorphology and morphometric studies of the pancreatic islet cells of diabetic rat treated with extracts of Annona muricata. Folia.Motphol 2010; 69(2): 92-100.

14. Ernst $S$, Demirci C, Valle $S$, et al. Mechanisms in the adaptation of maternal B-cells during pregnancy. Diabetes Manag (Lond) 2011; 1(2): 239-48.

15. Salvatierra CSB, Reis SRL, Pessoa AFM, et al. Short-term low-protein diet during pregnancy alters islet area and protein content of phosphatidylinositol 3-kinase pathway in rats. An Acad Bras Cienc 2015; 87: 1007-18.

16. Michau A, Hodson DJ, Fontanaud P, et al. Metabolism Regulates Exposure of Pancreatic Islets to Circulating Molecules In Vivo. Diabetes 2016; 65: 463-475.

17. Rieck S, White P, Schug J, et al. The Transcriptional Response of the Islet to Pregnancy in Mice. Mol Endocrinol 2009; 23:1702-12.

18. Butler AE, Cao-Minh L, Galasso R, et al.. Adaptive changes in pancreatic beta cell fractional area and beta cell turnover in human pregnancy. Diabetologia 2010; 53:2167 $-76$.

19. Huang C, Snider F, Cross JC. Prolactin receptor is required for normal glucose homeostasis and modulation of beta-cell mass during pregnancy. Endocrinology 2009; 150: 1618-26.

20. Johansson M, Mattsson G, Andersson A, et al. Islet endothelial cells and pancreatic beta-cell proliferation: studies in vitro and during pregnancy in adult rats. Endocrinology 2006; 147: 2315-24.

21. Gunasekaran U, Hudgens CW, Wright BG, et al. Differential regulation of embryonic and adult B-cell replication. Cell Cycle 2012; 13 : 2431-42.

22. Xiao X, Chen Z, Shiota C, et al. No evidence for beta cell neogenesis in murine adult pancreas. J Clin Invest 2013; 123: 2207-17.

23. Abood $\mathrm{AH}$. Histomorphometrical \&ultrastructural studies of B cells \& exocrine gland of mice pancreas in pregnancy \&postpartum periods. M.Sc. thesis. 2013; AlNahrain University, Iraq.

24. Bonner-Weir S, Weir GC. New sources of pancreatic -cells. Nat Biotechnol 2005; 23:85761.

25. Lee CS, De León DD, Kaestner KH, et al. Regeneration of pancreatic islets after partial pancreatectomy in mice does not involve the reactivation of neurogenin-3. Diabetes 2006; 55: 269-72.

26. Xu X, D'Hoker J, Stange G, et al. Beta cells can be generated from endogenous progenitors in injured adult mouse pancreas. Cell 2008; 132: 197-207.

27. Thorel F, Nepote V, Avril I, et al. Conversion of adult pancreatic alpha-cells to beta-cells after extreme beta-cell loss. Nature 2020; 464: 1149-54.

28. Eberhard D, Kragl M, Lammert E. 'Giving and taking': endothelial and B-cell in the islets of Langerhans. Trends Endocrinol Metab 2010; 21:457-63.

29. Jansson L, Barbu A, Bodin B, et al. Pancreatic islet blood flow and its measurement. Upsala J Medical Sciences 2016; 121: 81-95.

30. Hara A, Kadoya Y, Kojima I, et al. Rat Pancreatic Islet Is Formed by Unification of Multiple Endocrine Cell Clusters. Developmental Dynamics 2007; 236:3451-58.

31. Vasavada RC, Garcia-Ocaña A, Zawalich WS, et al. Targeted expression of placental lactogen in the beta cells of transgenic mice results in beta cell proliferation, islet mass augmentation and hypoglycemia. J Biol Chem 2000; 275:15399406.

32. Schraenen A, Lemaire K, Faudeur G, et al. Placental lactogens induce serotonin biosynthesis in a subset of mouse beta cells during pregnancy. Diabetologia 2010; 53(12): 2589-99.

33. Moldrup A, Petersen ED, Nielsen JH. Effects of sex and pregnancy hormones on growth hormone and prolactin receptor gene expression in insulin producing cells. 
Endocrinology 1993; 133:1165-72.

34. Kim H, Toyofuku Y, Lynn FC, et al. Serotonin regulates pancreatic $B$ cell mass during pregnancy. Nat Med 2010; 16:804-8.

35. Layden BT, Durai V, Newman MV, et al. Regulation of pancreatic islet gene expression in mouse islets by pregnancy. $\mathrm{J}$ Endocrinol 2010; 207:265-79.

36. Peschke E, Peschke D, Hammer T, et al. Influence of melatonin and serotonin on glucose-stimulated insulin release from perifused rat pancreatic islets in vitro. J Pineal Res 1997; 23:156-63.

37. Modi JP, Prentice H, Wu J-Y. Regulation of GABA Neurotransmission by Glutamic Acid Decarboxylase (GAD). Current Pharmaceutical Design 2015; 21: 4939 - 42.

38. Liguori M, Manchia M, Tondo L. The role of anti-glutamic acid decarboxylase autoantibodies in mood disorders. Neuroimmunol Neuroinflam 2015; 2: 237-48.

39. Wang C, Mao R, Van de Casteele et al. Glucagon-like peptide-1 stimulates GABA formation by pancreatic $B$-cells at the level of lutamate decarboxylase. Am J Physiol Endocrinol Metab 2007; 292: E1201-6. 